\title{
Thermodynamic modelling on the UHP metamorphism and fluid infiltration of the Tso Morari coesite- bearing eclogite in NW India
}

\author{
RUIGUANG PAN ${ }^{1}$, CATHERINE MACRIS ${ }^{2}$ AND MENOLD \\ CARRIE $^{3}$ \\ ${ }^{1}$ Indiana University - Purdue University Indianapolis \\ ${ }^{2}$ Indiana University-Purdue University Indianapolis \\ ${ }^{3}$ Albion College \\ Presenting Author: ruiguang.pan@gmail.com
}

The Tso Morari terrane within the Himalayan orogeny underwent ultrahigh-pressure (UHP) metamorphism due to northward subduction under the Eurasian continent during the early Eocene. The advancement of computational petrology and availability of relevant thermodynamic databases provide the mechanism to more precisely quantify metamorphic processes. In this study, we model the eclogite's prograde pressuretemperature $(P-T)$ path as well as multiple fluid infiltration events during exhumation using Theriak-Domino with dataset ds62 and garnet[1] and other metabasic mineral activitycomposition relations. The effect of garnet fractionation on the rock's effective bulk composition is considered in simulating prograde garnet growth. A "fishhook" shape clockwise $P-T$ path is obtained with a peak pressure of $\sim 28.5$ kbar at $\sim 563{ }^{\circ} \mathrm{C}$, followed by a peak temperature of $\sim 613{ }^{\circ} \mathrm{C}$ at $\sim 24.5 \mathrm{kbar}[2]$.

Thermodynamic modelling using $P-M\left(\mathrm{H}_{2} \mathrm{O}\right)$ pseudosections on Tso Morari eclogites indicates three distinct phases of fluid infiltration during exhumation. Fluid infiltration I occurs at $\sim 610$ ${ }^{\circ} \mathrm{C}$ and $\sim 23.5$ kbar with $\sim 3.1 \mathrm{~mol} \%$ fluid expulsion due to the destabilization of lawsonite. The modelling results are consistent with petrographic observations in the eclogite: we found $\sim 6.0 \mathrm{vol}$ $\%$ epidote and $\sim 21.0$ vol $\%$ amphibole and the possible preexistence of lawsonite evidenced by its pseudomorph (as epidote and paragonite aggregates) in a garnet core and rim[3], and CNASH modelling on the epidote and its inclusion paragonite. Fluid infiltration II occurs at $\sim 9.2 \mathrm{kbar}$ and $\sim 608{ }^{\circ} \mathrm{C}$ with $>2.6$ mol \% fluid infiltration at amphibolite-facies. This phase of fluid infiltration is characterized by aggressive amphibolization from the boudin core to rim. Fluid infiltration III occurs at $\sim 610{ }^{\circ} \mathrm{C}$ and $\sim 8.7 \mathrm{kbar}$, caused by breakdown of phengite as predicted through modelling the symplectitic association (plagioclase, biotite, and amphibole) surrounding omphacite. In summary, this study not only illustrates the application of thermodynamic modelling in quantifying metamorphic processes, but also the need of comparison between modeling predictions and petrographic observations.

[1] White et al. (2007), J Metamorph Geol 25, 511-527.

[2] Pan et al. (2020), Contrib Mineral Petrol 175, 1-28.

[3] St-Onge et al. (2013), J Metamorph Geol 31, 469-504. 